\title{
ECONOMIC EFFECTS OF THE SPALLATION NEUTRON SOURCE (SNS) AND THE JOINT INSTITUTE FOR NEUTRON SCIENCES (JINS) on The State of TenNessee
}

Prepared for the Tennessee Department of Economic and Community Development

February 1998 


\title{
ECONOMIC EFFECTS OF THE SPALLATION NEUTRON SOURCE (SNS) AND THE JOINT INSTITUTE FOR NEUTRON SCIENCES (JINS) ON THE STATE OF TENNESSEE
}

\author{
Prepared for the \\ Tennessee Department of Economic and Community Development
}

\author{
Prepared by the \\ Center for Business and Economic Research \\ The University of Tennessee, Knoxville
}

February 1998 


\section{ECONOMic EFFECTS OF The SPALlATION NEUTRON SOURCE (SNS) AND THE JoINT INSTITUTE OF NEUTRON SCIENCE (JINS) ON THE STATE OF TENNESSEE}

\section{Executive Summary}

This report provides an analysis of the economic impacts arising from the construction and operation of the Spallation Neutron Source (SNS) and Joint Institute of Neutron Science (JINS) facilities on the State of Tennessee. The study was conducted by the Center for Business and Economic Research (CBER) at the University of Tennessee, Knoxville, in cooperation with the Oak Ridge National Laboratory (ORNL) and the Science Alliance at UTK. Estimates provided are based on data provided by ORNL and the Office of Research at UTK. The estimates contained in the report quantify the income, employment, and sales tax revenue which will be generated by the activities of the SNS and JINS by accounting for the 1) direct impacts, those arising directly from the expenditures for the construction and operation of the facilities; 2) indirect impacts, those arising from the visitors to the facilities and from facility expenditures in Tennessee; and 3) multiplier impacts, those arising from the ripple effects created as new income is spent and respent in the state economy.

Key findings include the following:

- Seven-Year Construction Phase of SNS to Support a Total of 2,349 Jobs Annually

The construction of the SNS facility is projected to support an average of 2,349 jobs per year for each of the seven years of the construction phase. The primary jobs during construction will be labor and skilled craft jobs while the secondary and multipliergenerated jobs will be in a variety of sectors (including services and retail trade).

- Annual State Sales Tax Revenue Estimated to be \$3.6 Million per Year During Construction of SNS

Based on the assumption that 75 percent of the total material purchases will be made in the state and that all purchases of building materials and equipment in the state of Tennessee will be subject to the state sales tax, the average net present value of annual sales tax revenue generated for the seven-year construction project is estimated to be $\$ 3.6$ million. The total estimated sales tax revenue for the state over the seven-year span is $\$ 25.2$ million.

\section{- Ongoing Operations of the SNS Facility Estimated to Support 1,589 Jobs Annually}

The SNS facility's projected annual operating budget is \$100 million starting in 2006. The direct employment is projected to be 275 primary jobs of very high quality, mostly professional and technical jobs. The secondary and multiplier-generated jobs (including the visitor effect) from the operation are estimated to be 1,314 and will be in a variety of sectors in the business community. Provided the operating budget of the facility remains 
constant in real terms after the initial start-up, the created jobs will be maintained on a yearly basis.

Ongoing Operations of the SNS Facility Projected to Generate \$2.2 Million in State Sales Tax Revenue Per Year

The sales tax revenue from the direct effect and secondary effects, including visitors, is estimated to be $\$ 2.2$ million per year in net present value terms. In 2006 dollars, the sales tax revenue generated for the state is $\$ 4.4$ million. The sales tax revenue will accrue on an ongoing basis and can be expected to increase if the budget (in real terms) increases.

- Construction of JINS Projected to Support 305 Full-Time Jobs

The $\$ 8$ million projected construction budget of the JINS is estimated to support 174 labor and skilled craft jobs and 131 jobs in other sectors for a total of 305 jobs during the construction phase.

- Construction of the JINS Projected to Generate \$210,000 in State Sales Tax Revenue

The sales tax revenue generated from the construction of the JINS facility is estimated to be $\$ 210,000$, assuming the materials used in the construction of the facility will be taxexempt. The indirect effect accounts for $\$ 120,000$ while the remaining $\$ 90,000$ is attributable to the multiplier effect.

\section{Ongoing Operation of the JINS to Support 33 Jobs}

The annual operating budget of $\$ 1$ million for the JINS will support an estimated 33 jobs with 16 being above-average paying, professional jobs and the remaining 17 being elsewhere in the business community. The jobs estimated are on a per-year basis.

- Ongoing Operations of the JINS Projected to Yield Annual State Sales Tax Revenue of $\$ 19,000$

The income created as a result of the facility's operations is projected to generate $\$ 19,000$ in state sales tax revenue per year as it is spent in the economy. The revenue will be ongoing once start-up of the facility has taken place. 
TABLE A: Summary of Annual Impacts for the SNS Facility

\begin{tabular}{lcc}
\hline Impact & Construction & Operations \\
\hline Income & $\$ 69.9$ million & $\$ 7.9$ million \\
Employment & 2,349 jobs & 1,589 jobs \\
State Sales Tax Revenue & $\$ 3.8$ million & $\$ 2.2$ million \\
$\begin{array}{l}\text { Construction estimates are an average of the net present value of the impacts for } \\
\text { the } 6 \text {-year period. } \\
\text { Ongoing operations are scheduled to start in } 2006 .\end{array}$ \\
\hline
\end{tabular}

TABLE B: Summary of Annual Impacts for the JINS Facility

\begin{tabular}{lcc}
\hline Impact & Construction & Operations \\
\hline Income & $\$ 7.2$ million & $\$ 0.1$ million \\
Employment & 305 jobs & 33 jobs \\
State Sales Tax Revenue & $\$ 0.2$ million & $\$ 19,000$ \\
& & \\
\hline Construction estimates are based on a one year construction phase.
\end{tabular}




\section{ECONOMIC EFFECTS OF THE SPALLATION NEUTRON SOURCE (SNS) AND THE JOINT INSTITUTE OF NEUTRON SCIENCES (JINS) ON THE STATE OF TENNESSEE*}

\section{INTRODUCTION}

The Spallation Neutron Source (SNS) is an accelerator-based, next-generation, neutron source that is being designed for the Department of Energy's Office of Energy Research to meet the research and development needs of the scientific and industrial communities in the U.S. well into the next century. The SNS will produce the highest-flux, pulsed, neutron beams in the world. The Oak Ridge National Laboratory (ORNL) is leading the collaboration on this project which involves five DOE National Laboratories (Argonne, Brookhaven, Lawrence Berkeley, Los Alamos, and ORNL) in the design of SNS; ORNL will be responsible for the target, convention facilities, and overall project management and, with Argonne for the experiment systems. . SNS is expected to attract several thousand scientists and engineers each year from universities, private industry, government laboratories, and other nations. Consequently, the State of Tennessee has pledged $\$ 8$ million to ORNL and the University of Tennessee, Knoxville, to construct a Joint Institute for Neutron Sciences (JINS). This facility will serve as an intellectual focus for neutron science and a gateway for users of SNS by providing meeting facilities, offices, laboratories, a communications center, and housing for scientists and engineers visiting SNS.

With a projected construction budget of more than $\$ 825$ million to take place in Tennessee over six years and an annual operating budget of more than $\$ 100$ million starting in 2006, SNS will have significant, positive economic and qualitative impacts on the state of

*CBER would like to thank Pat Rader, ORNL; Dr. Ken Walker, Office of Research, UTK; Dr. Tom Callcott, Science Alliance, UTK; and the staff at Facilities Planning, UTK. Funding for this project was provided by Oak Ridge National Laboratory. 
Tennessee. The following study consists of a detailed analysis of the economic impacts that are projected to accrue to the state of Tennessee as a result of the construction and operation of the SNS and JINS facilities. Economic effects are measured on the basis of the impacts on the residents of the state and can be broken down into three main categories: (1) the income generated for residents, (2) the number of full-time equivalent jobs created within the state, and (3) the sales tax revenue generated for the state. In order to properly account for the impact of the two facilities, this study examines the direct, the indirect/visitor, and the multiplier effects for both the construction and operations phases of the two facilities. Additionally, the report will contain a brief discussion of the qualitative effects of the facilities on the State of Tennessee.

The remainder of the report is organized into seven parts. The next section will provide a background on the methodology used in assessing the income, employment, and tax revenue generation process. The impacts attributed to the SNS facility will be detailed in sections III and IV, with section III focusing on the construction phase and section IV detailing the operations phase. Sections V and VI will provide an analysis of the JINS facility, with section V detailing the construction phase and section VI summarizing the effects of the annual operations. Section VII discusses some of the major qualitative impacts, and section VIII is a brief conclusion.

\section{METHODS FOR EVALUATING ECONOMIC IMPACTS}

The proposed SNS and JINS facilities will have three measurable economic impacts on the state economy: direct, visitor/indirect, and multiplier. Direct effects are those attributable to the construction and operation expenditures of the facilities themselves. These direct effects will 
include the hiring of staff; purchasing of materials, supplies, and services; and the sales taxes paid on these purchases. Visitor effects, or indirect effects, arise from the expenditures made by persons visiting the SNS and JINS facilities. Based on the estimates for visitors, 4,000 annually with 2,000 attending conferences and another 2,000 using the experiment facilities, the visitor impact will be significant. The projected average duration of stay for visitors to the facilities is seven days and, using expenditure data provided by the Knoxville Convention and Visitors Bureau, it is estimated that, on average, overnight visitors will spend $\$ 135$ per day. Given that the major portion of these expenditures are incurred at hotel/motel and eating/drinking establishments, it is worth noting that 43 cents of every one dollar spent by visitors will become personal income to a resident in the state, thus accounting for the indirect income and employment impacts.

Finally, the multiplier, or ripple effect, occurs as the direct and indirect income generated is spent and respent within the local economy. For example, when wages and salaries are paid to the employees of the facilities, those employees spend a significant portion of their earnings in the state on goods and services such as housing, clothing, and food. In turn, the owners of the businesses receiving these payments pay their employees and the cycle continues. During each round of subsequent spending, a portion of the direct and indirect income leaks out of the state economy through taxes, savings, and payments to non-residents. For the purpose of this study, the multiplier used is 1.75 . The total income, employment, and tax revenue impacts will be computed by summing up the direct, visitor/indirect, and multiplier effects detailed above. 


\section{IMPACTS OF THE CONSTRUCTION OF THE SNS FACILITY ON TENNESSEE}

The construction of the SNS facility

has a projected budget of more than $\$ 1.1$

billion with over $\$ 825$ million being

allocated to the Tennessee site spanning over

a six-year period. For the purpose of the

impact calculations, the construction

expenditures were discounted using a

discount rate of 8.25 percent which

corresponded to the rate reported for ten-year

Treasury Strip Bonds in The Wall Street

Journal on February 17, 1998. The net

present value of the construction budget

allocated to Tennessee was calculated to

be $\$ 609.7$ million. Other important

assumptions made in the calculations of

the impacts are included in Table 1.

The average annual personal

income impact of the six-year

construction phase is $\$ 69.9$ million

dollars (see Figure 1). The direct and
TABLE 1: Assumptions Used in

Calculating the Impacts of the

Construction of the SNS Facility

75 percent of all materials used in the construction will be purchased in Tennessee.

All building materials and equipment purchased in Tennessee will be salestaxable.

The average salary used to estimate the employment impacts were calculated using relevant industry data in 1998 dollars.

Sales tax calculations allow for a 15 and 4 percent leakage for taxes and savings, respectively.

55 percent of income is spent on salestaxable verses non-taxable goods.

A multiplier of 1.75 was utilized.
Figure 1: Total Income Generated by the Construction of the SNS Facllity In Tennesse Direct/Indirect

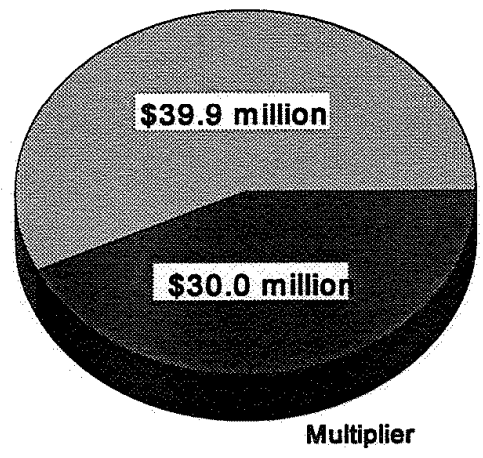


indirect effects of the payroll and non-payroll expenditures will generate more than $\$ 39.9$ million in new personal income for Tennesseans. As the new income is spent and respent in the state economy, an additional $\$ 30.0$ million in new income will accrue to the state. In comparison, a study conducted by CBER in 1997 estimated that the annual personal income impact of five local manufacturing firms ( American Safety Razor, Daikin Drivetrain, Imperial Wall Covering, Oozx, PBR Automotive, and United States

Cellular) to be $\$ 32.5$ million. ${ }^{1}$

The additional income generated by the construction of the SNS facility will translate into job creation for the state. On average, the construction of the facility will support 2,349 new jobs per year over the sixyear construction horizon. The direct jobs, consisting of laborers, skilled workers, engineers, and other professionals, will account for 779 jobs per year while the remaining 1,570 jobs will accrue to the indirect and multiplier effects (see Figure 2). These jobs will be located throughout the business community. A significant portion of the construction budget is designated for high-salary staff, thus leading to employment effects which are higher than usual relative to a representative manufacturing firm.

${ }^{1}$ Matthew N. Murray and David Mayes, Business Recruitment and its Impact on the Knoxville and Knox County Economies, CBER, University of Tennessee, Knoxville, May 1997. 
The final economic impact to be evaluated for the construction phase is the generation of state sales tax revenue. The project is estimated to yield $\$ 3.6$ million annually in state sales tax revenue over the six-year period. As depicted in Figure 3, of the total, ORNL's direct payment of sales tax to the state for the purchase of
Figure 3: Annual State Sales Tax Revenue

Generated During Construction of the SNS

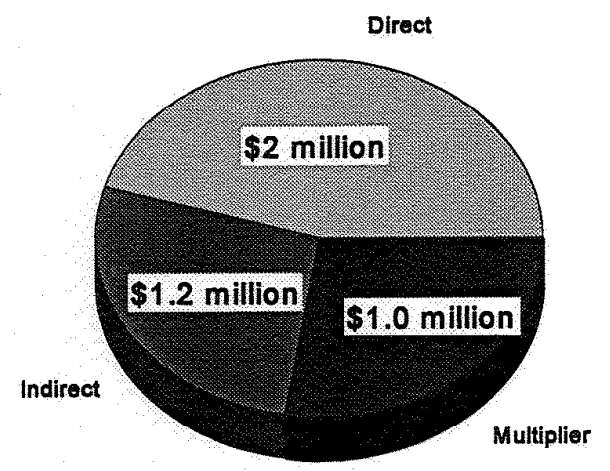

materials in Tennessee is estimated to average $\$ 1.7$ million annually. The indirect and multiplier effects will generate the remaining $\$ 1.9$ million. The total state sales tax revenue for the entire construction phase is estimated to be $\$ 25.1$ million. Again, it is worth noting that these calculations have been discounted to 1998 dollars since the revenue will not be realized until some time in the future.

\section{IMPACTS OF THE ONGOING OPERATIONS OF THE SNS FACILITY ON TENNESSEE}

Operations at the SNS facility are

scheduled to begin in 2006 with a projected annual budget of $\$ 102.2$ million (in 2006

dollars). The budget, broken down by major expenditure categories, is depicted in Table 2.
TABLE 2: Project Annual Budget for the SNS Facility (in 2006 dollars)

\begin{tabular}{lr} 
Expenditure Category & Costs \\
\hline Staff & \\
Utilities & $\$ 34,334,000$ \\
Supplies & $20,350,000$ \\
Travel & $1,717,000$ \\
Equipment & $1,716,000$ \\
Overhead & $16,715,000$ \\
\hline Total & $27,318,000$ \\
\hline Based on information provided by ORNL
\end{tabular}


In addition to the direct, indirect, and multiplier effects, the ongoing operations of the facility will generate visitor effects. Visitors to the SNS, projected to be 4,000 annually, were divided into two categories - those attending conferences and those conducting experimental research. It is assumed that 2,000 of the annual visitors will be conducting experimental research and will have access to housing and eating establishments at the JINS; therefore, no visitor effect was calculated for the visitors falling in that category since their expenditures will be accounted for through the expenditures of the JINS. Based on estimates provided by the Knoxville Convention and Visitors Bureau, the expenditures for the remaining 2,000 are assumed to average $\$ 135$ per day for lodging, meals, entertainment, and miscellaneous purchases. Additionally, ORNL projects the average duration of stay to be 7 days.

The annual personal income impact in Tennessee attributable to the operation of the SNS facility is estimated to be $\$ 47.4$ million, with the direct impact constituting a net present value of $\$ 19.7$ million. The significant

Figure 4: Annual Income Impacts In Tennessee from the Operations of the SNS Facility

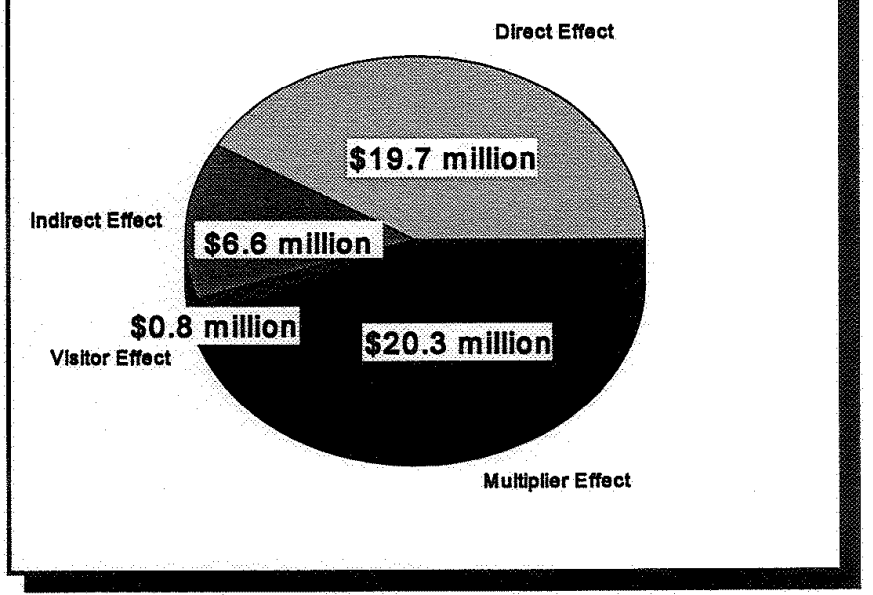
expenditures allocated for wages and salaries of staff leads to higher than usual direct income effect. Figure 4 depicts the annual breakdown of new income by impact category.

The new income created leads to new job creation. As illustrated in Figure 5, the total jobs supported in Tennessee by the annual operations of the facility is projected to be 1,589 . The 
SNS facility itself is projected to staff 275 full-time positions with the majority being high-paying, professional jobs. The remainder of the operating budget will indirectly support 298 full-time equivalent jobs while the visitor and multiplier effects will support the remaining 1,016 . These jobs will be throughout the state in a variety of sectors including retail trade and services. Providing that the operating budget remains constant in real terms over time, the employment impacts can be expected to be maintained on a yearly basis.

The third economic impact arising from the operation of the SNS facility is the generation of tax. For this specific project, the only tax evaluated was the state sales tax.

The total state sales tax revenue generated as a result of operations is estimated to be $\$ 2.2$ million on an annual basis (see Figure 6). Again, the direct sales tax, totaling $\$ 1.6$ million, assumes that purchases made for the operation of the facility will be
Figure 5: Summary of the Annual Employment Impacts of the Operation of the SNS Facillty Indirect

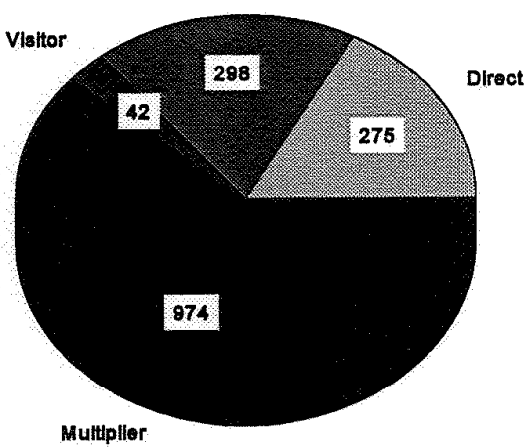
Full-Time Jobs 
primarily in Tennessee and that all will be sales-taxable. The visitor effect assumes that all expenditures will be sales-taxable while the multiplier effect assumes that 55 percent of the new income created will be spent on sales-taxable goods.

\section{ECONOMIC IMPACTS OF THE CONSTRUCTION OF THE JINS FACILITY}

The Joint Institute of Neutron Science is a joint effort between ORNL and the University of Tennessee, Knoxville and will serve as an on-site user facility to serve the needs of visitors to the SNS facility, will maintain an active visiting scientist program, and will provide conferences and seminars in neutron science. The projected construction budget of the facility is $\$ 8$ million with the majority of expenditures assumed to take place in Tennessee. The total income impact

Figure 7: Summary of Income impacts for Construction Phase of the JINS Facility

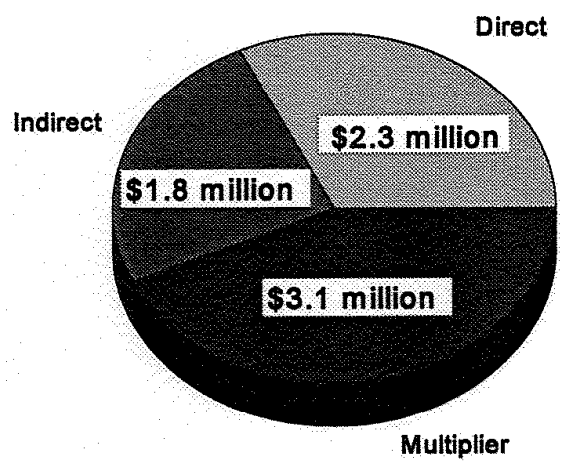
from the construction is estimated to be $\$ 7.2$ million (see Figure 7 ). The direct income, arising from expenditures on labor, accounts for $\$ 2.3$ million. The indirect income, arising from nonlabor expenditures, accounts for $\$ 1.8$ million and the remaining $\$ 3.1$ million will accrue to the multiplier effect.

As depicted in Figure 8, the $\$ 7.2$ million in new income is estimated to support a total of 305 full-time equivalent jobs. Direct jobs, totaling 114 will primarily be laborers and skilled 
craftsman. The remaining 191 indirect and multiplier-generated jobs will be elsewhere in the business community. The construction phase of the JINS is assumed to be one year, therefore, if the construction phase is longer, the total employment impact would be spread over the entire time span according to the flow of expenditures.
Figure 8: Summary of Employment Impacts of the construction of the JINS Facility Full-TIme Jobs

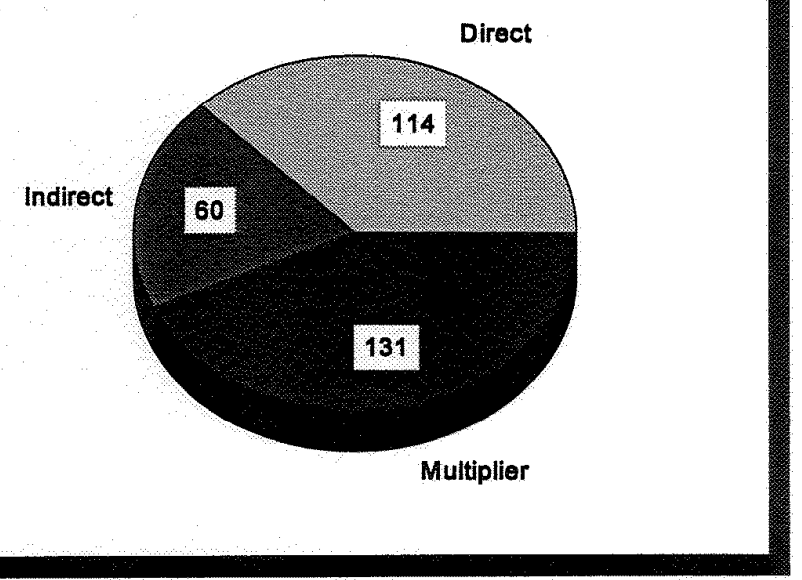

The construction of the JINS facility is assumed to be tax-exempt, however, the state will still benefit from the generation of sales tax revenue via the indirect and multiplier effects. The total sales tax revenue projected for the state during construction is $\$ 0.2$ million (see

Figure 9). It is assumed that a total of 64 percent of the new income generated is not exposed to the sales tax due to leakages for taxes, savings, and purchases of non-sales taxable goods

Figure 8: Summary of the State Sales Tax Revenue Generated from Construction of JINS

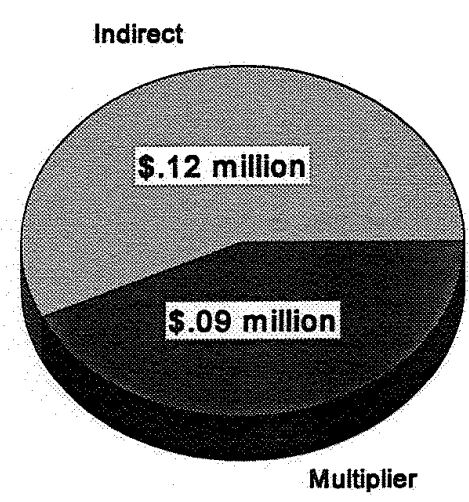
and services. 


\section{IMPACTS OF THE ANNUAL OPERATIONS OF THE JINS FACILITY}

The JINS is projected to have an annual operating budget of $\$ 1$ million. A

preliminary breakdown of the operating budget into major expenditure categories was not available at the time the study was
TABLE 3: Annual Operating Budget for the JINS Facility

\begin{tabular}{lr}
\hline Expenditure Category & Costs \\
\hline Staff & $\$ 300,000$ \\
Utilities & 200,000 \\
Communications & 200,000 \\
Supplies & 150,000 \\
Miscellaneous & 150,000 \\
\hline TOTAL & $\$ 1,000,000$
\end{tabular}

conducted; therefore, the assumptions regarding spending were based on percentages for convention facilities obtained from the 1992 Census of Service Industries and on the spending patterns of the SNS facility. Table 3 displays the budget expenditures by category used in the calculations of the economic impacts.

The operation of the JINS is projected to create $\$ 0.7$ million in new income for residents of the state of Tennessee. A breakdown of the annual income by impacts category is provided in Figure 10. The direct income impact reflects the actual wages and salaries paid to the employees of the facility,

Figure 10: Summary of the Annual income Impacts from the Operations of the JiNS

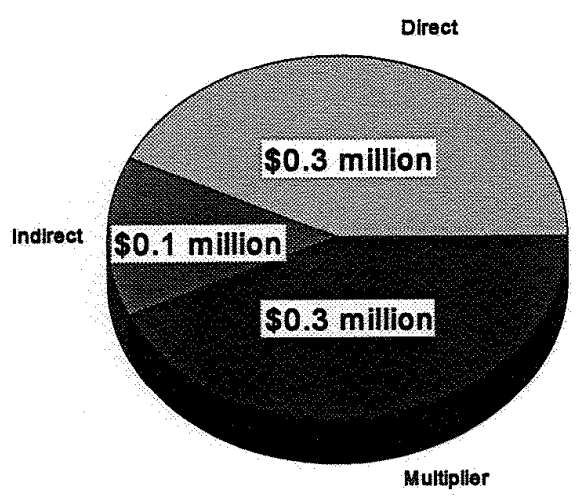
while the indirect effect reflects the income generated from non-payroll expenditures in the state. 
The new income created is projected to support 33 full-time equivalent jobs annually. The direct effect will account for 16 jobs while the indirect and multiplier effects will support the remaining 17 jobs. The salaries of the direct jobs are anticipated to be in line with the average wage for workers in the
Flgure 11: Summary of the Annual Employment

Impacts from the Operations of the JINS

Full-TIme Jobs

Direct

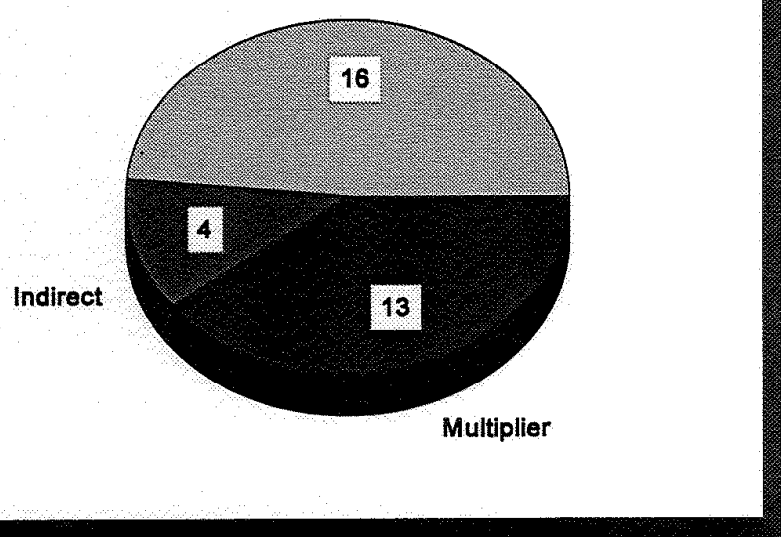

convention service industry. The remaining jobs will be in other sectors of the regional economy.

Finally, the state sales tax revenue impact arising from the ongoing operations of the JINS are projected to be $\$ 19,000$ annually. Again, this assumes that purchases for the JINS will be tax exempt since it will be overseen by the University of Tennessee. There is potential for growth if the number of visitors increases beyond the projected 2,000 per year.

\section{QUALITATIVE IMPACTS OF THE SNS AND JINS FACILITIES ON TENNESSEE}

In the above analysis, we have narrowly quantified the economic activity associated with the construction and operation of the SNS and JINS facilities for the State of Tennessee. In addition, there exist many qualitative impacts to the state, perhaps the most notable being agglomeration along with visibility and prestige. Agglomeration impacts would arise from the industrial implications of the neutron research which would be taking place. There are currently 
over 45 major U.S. corporations that use applied research emerging from neutron facilities in their operations. Having the premier neutron research facility located in Tennessee would enhance the state's competitive position to attract these firms to locate within the state. The competitive advantage would be strengthened by the existence of a high quality labor force resulting from the top researchers in the field being at the facility and the presence of a mutually beneficial infrastructure.

The location of the SNS and JINS in Tennessee would also result in high visibility and prestige for the state and, combined with the existing high flux isotope reactor at ORNL, Tennessee would possess the Western Hemisphere's only source of many commercially significant isotopes for medical application, aerospace, agriculture, industrial technology, and national security. ${ }^{2}$ These combined neutron facilities are to be among the best in the world and will bring international recognition to Tennessee in the area of neutron sciences for the work to be conducted at ORNL and UTK. In addition, the University of Tennessee will benefit greatly from the existence of facilities through expanded research capabilities and academic programs. UTK could become one the world's most recognized centers for neutron sciences, with the benefits extending to nearly all of the university's science and engineering departments.

\section{CONCLUSION}

The existence of the Spallation Neutron Source and the Joint Institute for Neutron Science would provide the State of Tennessee with significant economic and qualitative benefits. It would potentially enable the state to continue its effort to diversify its economic base by

${ }^{2}$ Science Alliance, UT and the ANS, University of Tennessee, Knoxville. 
enhancing the state's labor force with top quality professional scientists and engineers and gaining international attention. The economic benefits would begin accruing at the start of construction and continue throughout the life of the project. When compared to the construction and operation of an average manufacturing firm, the proposed SNS and JNS facilities surpass the economic benefits accrued to the state. Real growth in the magnitude of the operations of the facility leads to the opportunity to expand the economic benefits to the residents of the state. In addition, the facilities would provide excellent teaching and training opportunities to the academic environment. The University of Tennessee stands to gain through the expansion of graduate programs in neutron sciences and related fields, the attraction of highly qualified faculty members, and the bolstering of their international reputation. 